\title{
NIH scrutinizes benefits of technology transfer
}

WASHINGTON, D.C.-Technology-transfer agreements that enable private-sector companies to commercially develop federally sponsored research are being examined by the National Institutes of Health (NIH, Bethesda, MD). A panel recently convened by the NIH recommended that the NIH develop general guidelines to help universities and other institutions avoid potential problems from these agreements, which are mandated by the Bayh-Dole Act of 1980 .

The creation of the NIH panel, as well as an internal NIH task force, trace to a 1993 inquiry from Representative Ron Wyden (D-OR). Wyden expressed particular concerns regarding a technology-transfer agreement between the Scripps Research Institute (San Diego, CA) and Sandoz Pharmaceuticals (E. Hanover, NJ), a U.S. subsidiary of Sandoz (Basel). The agreement calls for Sandoz to fund research at Scripps to the tune of $\$ 300$ million over 10 years. In return, Sandoz gets commercial rights to much of the research under way at Scripps. Yet the NIH also supports Scripps researchers, with overall NIH funding ranging from $\$ 60-100$ million a year during the recent past.

NIH officials looked at the Scripps-Sandoz agreement in the context of some 375 other technology-transfer agreements between NIH grantee institutions and companies. They conclude that the size and scope of the Scripps-Sandoz agreement set it apart from the other agreements, making it an "aberration that is unlikely to be duplicated." Indeed, most of the 375 agreements are small in scale. And even the 44 of these agreements that are classified as large fall short of the Scripps-Sandoz deal.

Without a doubt, Bayh-Dole has helped to fuel patenting and licensing activities at universities. The law accords universities the commercial rights to federally funded research conducted by their faculty, and it encourages universities to seek private-sector partners to develop faculty discoveries into commercial products to benefit the general public. Yet as federal funding of university research has tended to level off during recent years, many universities have pursued technology-transfer agreements more aggressively, hoping to find alternative sources of funding to support their research, as well as other of their activities.

In fact, by making cutting-edge technology readily available, BayhDole is credited with helping to stimulate the rapid growth of the U.S. biotechnology industry, points out Alan Goldhammer of the Biotechnology Industry Organization (Washington, DC). The transfer of numerous federally funded university discoveries to numerous biotech companies has also resulted in new jobs and new products for consumers, according to Goldhammer.

Lately, however, the zealous implementation of Bayh-Dole is raising concerns at universities, according to Paul Berg of Stanford University (Stanford, CA). At times, university faculty are shifting young researchers away from fundamental work to more commercially attractive applied problems, thereby endangering the pace of fundamental discoveries, contends Berg. He adds that, in their haste to patent commercially attractive basic discoveries, university faculty, furthermore, are not making these discoveries public and are, thus, slowing progress in some of the most swiftly developing areas of biology.

Although the NIH panel offered no sure-fire remedies for these problems, it did encourage the NIH to provide guidance on technology transfer to grantee institutions. It also advised heightened scrutiny of all "mega-scale" technology-transfer agreements and perhaps all such agreements that meet several threshold criteria. These criteria would involve those agreements with funding in excess of $\$ 5$ million a year or $\$ 50$ million overall, those agreements involving several principal investigators or whole departments, and those agreements that call for commercial rights to technology developed over multiyear periods. -Joseph Alper
The NIH should

provide guidance

on technology

transfer to grantee

institutions and

should scrutinize

all "mega-scale"

technology-transfer

agreements.

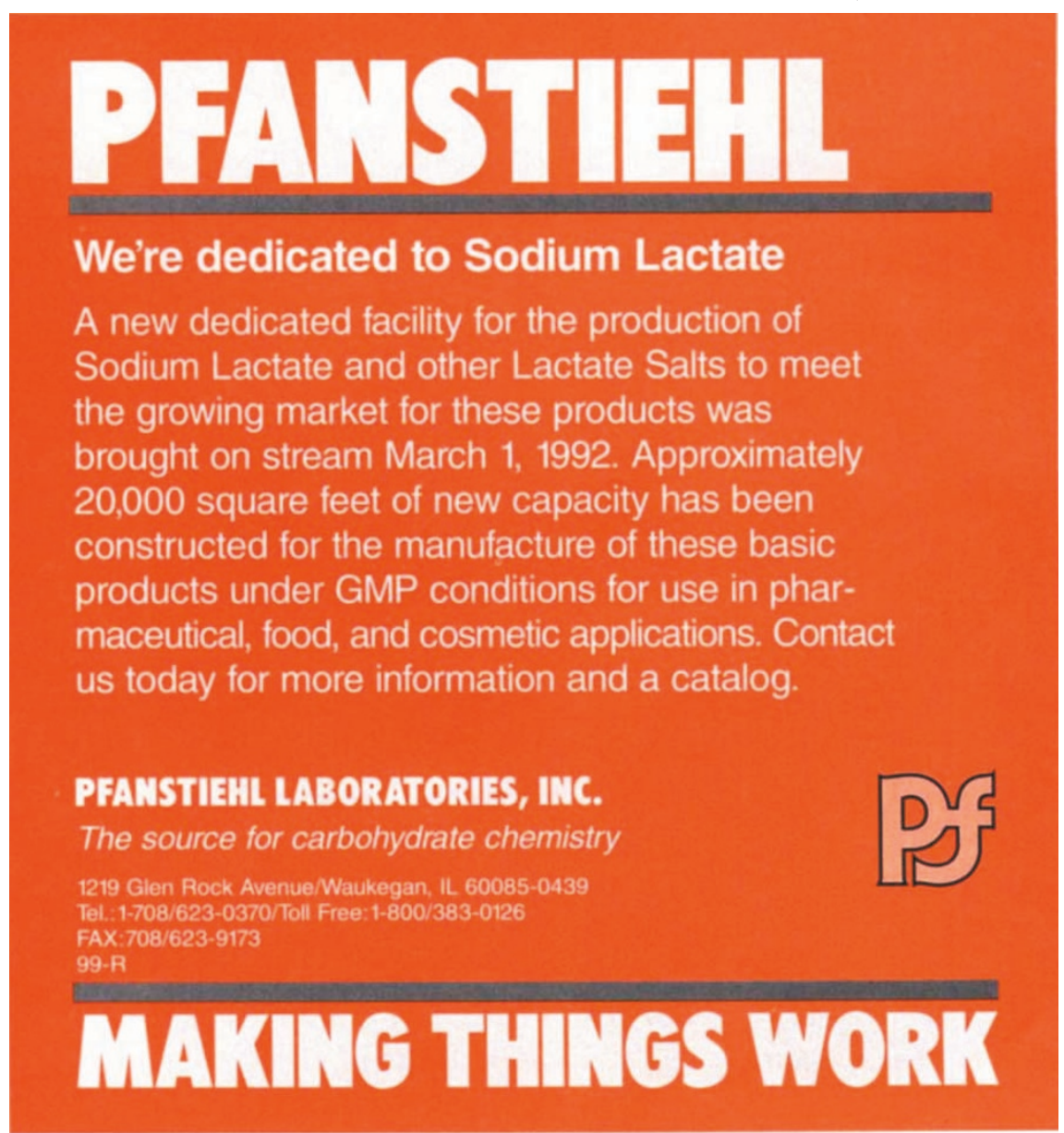

Write in No. 538 on Reader Service Card 